\title{
Thrombotic Thrombocytopenic Purpura with Mixed Connective Tissue Disease - Non-immune Hemolytic Anemia with Autoimmune Disease - Rare Case Report
}

\author{
MAB MOMIN $^{\mathrm{a}}$, B S K PRUSTY ${ }^{\mathrm{b}}$, AMITHA REDDY $^{\mathrm{c}}$
}

Summary:

TTP (Thrombotic Thrombocytopenic purpura) is a nonimmune, microangiopathic hemolytic anemia (MAHA), associated with thrombocytopenia, fever, neurologic or renal dysfunction. Mixed connective tissue disease (MCTD) is not a specific disorder and identified serologically by high titers of of antibodies to RNP. Coexistence of TTP with asymptomatic MCTD is rare encounter. We describe here a rare case of secondary TTP in a 42 year, old female presenting as menorrhagia for seven days, severe headache and one episode of seizure. This case emphasizes the early diagnosis

Introduction:

Thrombotic microangiopathies is a clinical syndromes that includes TTP and HUS.These are mechanical hemolytic anemia in which red cell fragmentation is due to contact between red cells and abnormal intima of partially thrombosed narrowed small vessels. TTP presents with transient neurological manifestation while in HUS dominance of acute renal failure seen. This is due to different distribution of microvascular lesion [1].

MCTD is an autoimmune disease identified as coexistence features of SLE, Polymyositis and systemic

a. Dr. Majed Abdul Basit Momin, Consultant pathologist, Yashoda Hospital, Malakpet, Nalgonda x-roads, Hyderabad - 500036. Email id : majedmomin9@gmail.com, Phone no. : 9849076574 , Institute :

b. Dr.B Saroj Kumar Prusty, Cosultant Intensivist, Yashoda Hospital Malakpet, Email: sarojprusty1@gmail.com, Mobile no. 9440721690

c. Dr.Amitha Reddy, Consultant Microbiologist, Yashoda hospital ,Malakpet branch, Hyderabad. Mail: amitha23@yahoo.com, Phone no. : 9000655284

Address of Correspondence: Dr.Majed Abdul basit Momin, Consultant Pathologist, Department of Laboratory Medicine, Yashoda hospital, Malakpet. Nalgonda x-roads, Hyderabad 500036, Mobile No: 9849076574 ,

Email: majedmomin9@gmail.com

Received: 27 Sept., 2018

Accepted: 25 Sept., 2019 of TTP and its association with underlying condition for proper management and to avoid fatal outcome.

KeyWords: Microangiopathic hemolytic anemia (MAHA); Thrombotic Thrombocytopenic purpura( TTP); hemolytic uremic syndrome(HUS); Mixed connective tissue disease(MCTD); U1-Ribonucleoprotein (RNP); Antineuclear antibody(ANA); $A$ disintegrin and metalloproteinase with a thrombospondin type 1 motif,member 13(ADAMTS 13)

(J Bangladesh Coll Phys Surg 2020; 38: 46-48)

DOI: http://dx.doi.org/10.3329/jbcps.v38i1.44688

sclerosis. Diagnosis of MCTD is supported by detecting anti-RNP in serum [2]. Secondary TTP is seen in bone marrow transplantation, malignancy, pregnancy, infections and drugs. Coexistence of TTP with MCTD is rarely described in review of literature till date.

\section{Case Report :}

A 44-years old woman was admitted to emergency department with per vaginal bleed for seven days, headache with one episode of seizure associated with tongue bite and altered sensorium for two days. Patient admitted initially in nursing home, her $\mathrm{CT}$ scan brain was done, which show normal findings. On general examination she was drowsy, disoriented and irritable. She was mildly anaemic,icteric and tongue showed ecchymosis,. The temperature was $99^{\circ} \mathrm{F}$, pulse $80 \mathrm{~b} /$ min, blood pressure $110 / 70 \mathrm{~mm}$ of $\mathrm{Hg}$ and respiratory rate $24 / \mathrm{min}$. Systemic examination revealed normal findings except CNS examination which show altered sensorium.

Laboratory hematological investigations show bicytopenia (Hemoglobin $6.7 \mathrm{gm} / \mathrm{dl}$ and severe thrombocytopenia 12000/cumm). Peripheral blood film examination reveal normocytic, mild hypochromic RBCs with presence of schistocytes (Helmet shaped RBCs 
and triangular form of RBCs)( Figure1). Reticulocyte count are increased (10\%). Both direct and indirect coomb's test are negative. Coagulation study was with in normal limit.

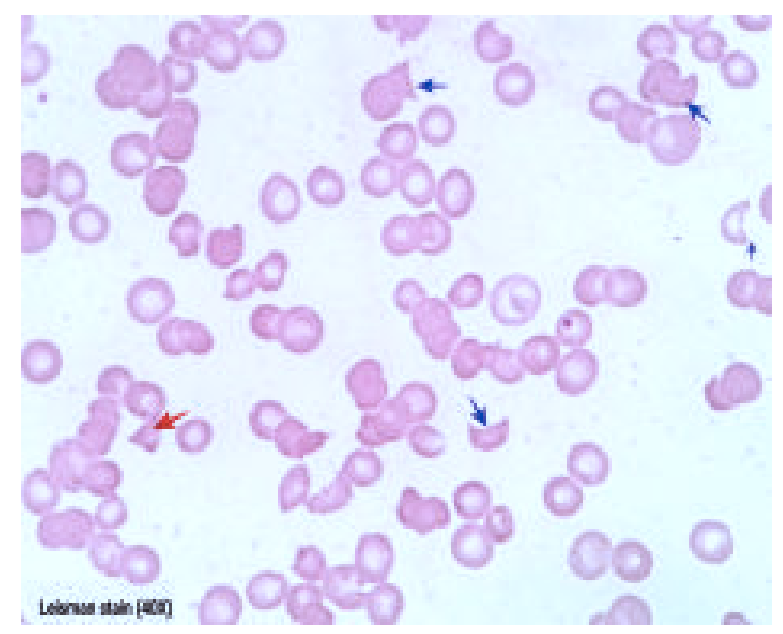

Figure :1; Peripheral blood smear (leishman stain 40X) show fragmented RBCS-Helmet shape (blue arrow) and Triangular shape (red arrow)

Biochemical parameters revealed increased total bilirubin $4.4 \mathrm{mg} / \mathrm{dl}$ (Direct $0.3 \mathrm{mg} / \mathrm{dl} \&$ Indirect $4.1 \mathrm{mg} / \mathrm{dl}$ ) normal liver enzymes, alkaline phosphatase and total serum proteins. Serum creatinine was $0.6 \mathrm{mg} / \mathrm{dl}$ and blood urea was $16 \mathrm{mg} / \mathrm{dl}$. Serum electrolytes were normal. Serological investigation was negative for HIV, HBsAg and HCV. ANA/IF positive for antinuclear antibodies with nuclear speckled with nucleoli $3+$,cytoplasm granular 1+ seen (Figure 2)

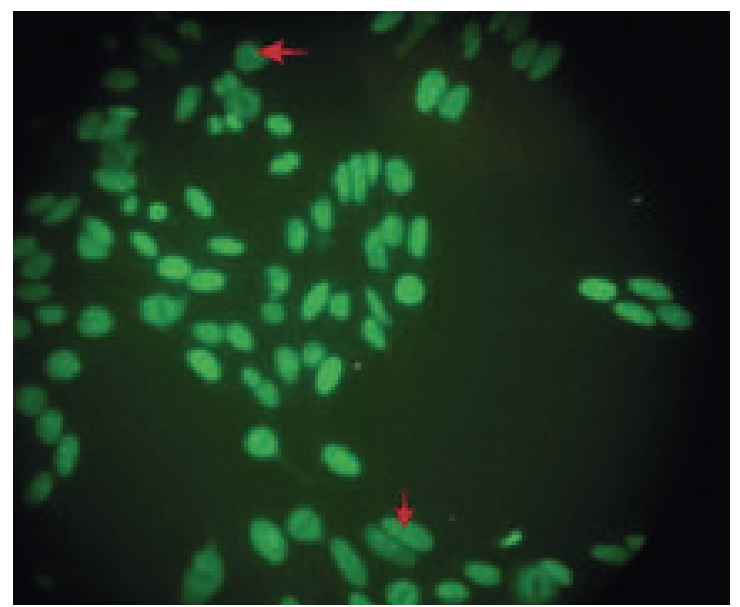

Fig.-2 Immunofluorescent Microscopy for ANA/IF,show prominent nucleoli (red arrows)
ANA profile was positive for anti U1-RNP. Anti- Sm, Anti SS-A, SS-B ,Anti Ro-52 recombinant. antobodies were negative for Sci-70,PM-Scl100,Jo-1, Centromere B, PCNA, anti-Ds DNA, nucleosomes ,histones, Ribosomal $\mathrm{P}$ protein and AMA-M2 also negative.

Radiological examination including chest $\mathrm{X}$ ray, abdominal and pelvis scan reveal normal study. Based on clinical ,hematological and serological findings, diagnosis of TTP with MCTD is considered and treated as a case of secondary TTP. Patient was intubated and connected to ventillatory support and with in an hour of admission, plasmapheresis was initiated with 2 lit of FFP replacement, two units of packed cell transfusion and intravenous methyl prednisolone. Inspite of three session of plasmapheresis with FFP as replacement, patient went to cardiac arrest and could not be revived and declared death.

\section{Discussion:}

Hemolytic anemia related to RBCs fragmentation and thrombocytopenia is defined under microangiopathic hemolytic anemia (MAHA). The commonest diagnosis related to this is TTP and HUS. TTP may be congenital(very rare) or acquired. Acquired cases are divided into idiopathic and secondaryTTP.Classical pentad in TTP includes Thrombocytopenia, MAHA, fever(25\%),neurological symptoms $(80 \%)$ and renal dysfunction(30\%). Majority (90\%) cases do not have all five clinical features. MAHA and thrombocytopenia are enough to suspect the diagnosis of TTP [3]. As seen in this case with neurological features help in early diagnosis of TTP.

The hallmark of MAHA is the development of schistocytes ( Helmet and triangular form of RBCs) seen in peripheral blood film. The pathogenesis is believed to start with the formation of microthrombi and platelet and fibrin mesh in the vessels of smaller diameter, such as arterioles and capillaries. During the passage of erythrocytes through these partially obstructed blood vessels, severe damage to the erythrocyte wall occurs and results in cell lysis and fragmentation[4]. The ICSH Schistocyte Working Group agreed that a schistocyte percentage above $1 \%$ in a peripheral blood smear in adults is a robust cytomorphological indication in favor of a diagnosis of thrombotic microangiopathies, when additional features suggesting an alternative diagnosis are absent.[5] . ADAMTS13 deficiency is related to 
pathogenesis of TTP. In review of literature, many patient who fulfill clinical and lab diagnostic criteria for TTP, do not have ADAMTS13 deficiency[6]. In our case ADAMTS13 deficiency could not be performed because of non-availability of the test and financial status of patient.

Acquired TTP need to rule out associated secondary diseases like SLE (most common), antiphospholipid antibody syndrome, adult onset stills diseases, rheumatoid arthritis, systemic sclerosis, sjogren syndrome, polymyositis and dermatomyositis. TTP with mixed connective tissue disease are rare and possible pathogenesis is higher prevalence of antiendothelial cell antibodies in sera of MCTD cases and decreased plasma fibrinolytic activity [7].

The initial management of TTP includes supportive care. Definitive management is with plasmapheresis \& Eculizumab, a monoclonal antibody to C5. Plasmapharesis has been thought to be effective due to its ability to remove mutated proteins and antibodies to complement factor $\mathrm{H}$ and restore the patient's blood with normal complement proteins and is most effective when initiated within the first 24 hours[8].In addition, corticosteroid treatment is effective to reduce the activity of auto-antibodies especially in association with MCTD.

Prognosis in such secondary TTP, based on old reported cases is poor, Mortality was high (45\%),females are commonly affected with serious neurological involvement including seizure and coma. The present case had seizure and altered sensorium and initial early diagnosis could not be done outside.

\section{Conclusion:}

To conclude, TTP is hematological emergency and its association with MCTD is rare. Clinicians should not exclude diagnosis of TTP based on classic pentad of clinical features. Since peripheral blood film schistocytes and thrombocytopenia with negative coomb's test are strong indicator TTP. As TTP with MCTD has high mortality, early diagnosis and prompt treatment is essential to avoid fatal outcome.

\section{References:}

1. Firkin, F., Chesterman, C., Rush, B., \& Pennigton,D. (2008). De Gruchy's Clinical haematology inmedical Practice. John Wiley \& Sons.

2. PathologyRobbins Pathologic Basis of Disease. JAMA. 1999;282(18)

3. Kessler CS, Khan BA, Lai-Miller K. Thrombotic thrombocytopenicpurpura: a hematological emergency. J Emerg Med 2012; 43(3):538-544.

4. Marcur, A. J.: Haemorrhagic Disorders: Abnormalities of platelet and vascular function.In "Cecil Textbook of Medicine”, Editors: J. B. Wyngaarden and L. H. Smith, 17th Edition, W. B. Saunders Co. Philadelphia, London and Toronto, 1985, pp. 1028-1040.

5. ICSH recommendations for identification, diagnostic value, and quantitation of schistocytes.Int. Jnl. Lab. Hem. 2012, 34, 107-116

6. S. K. Vesely, J. N. George, B. Lammle et al., "ADAMTS13 activity in thrombotic thrombocytopenic purpurahemolyticuremic syndrome: relation to presenting features and clinicaloutcomes in a prospective cohort of 142 patients," Blood, vol.6 102, no. 1, pp. 60-68, 2003.

7. T. Matsuyama, M. Kuwana, M. Matsumoto, A. Isonishi, S.Inokuma, and Y. Fujimura, "Heterogeneous pathogenic processesof thrombotic microangiopathies in patients with connectivetissue diseases," Thrombosis \& Haemostasis, vol. 102,no. 2, pp. 371-378, 2009.

8. George JN. How I treat patients with thrombotic thrombocytopenicpurpura: 2010. Blood J 2012. 